\title{
Proposal of a New Parameter for the Weathering Characterization of Carbonate Flysch-Like Rock Masses: The Potential Degradation Index (PDI)
}

\author{
M. Cano ${ }^{1} \cdot$ R. Tomás ${ }^{1}$
}

Received: 24 September 2015/Accepted: 8 January 2016/Published online: 23 January 2016

(c) The Author(s) 2016. This article is published with open access at Springerlink.com

\begin{abstract}
The susceptibility of clay bearing rocks to weathering (erosion and/or differential degradation) is known to influence the stability of heterogeneous slopes. However, not all of these rocks show the same behaviour, as there are considerable differences in the speed and type of weathering observed. As such, it is very important to establish relationships between behaviour quantified in a laboratory environment with that observed in the field. The slake durability test is the laboratory test most commonly used to evaluate the relationship between slaking behaviour and rock durability. However, it has a number of disadvantages; it does not account for changes in shape and size in fragments retained in the $2 \mathrm{~mm}$ sieve, nor does its most commonly used index $\left(\mathrm{Id}_{2}\right)$ accurately reflect weathering behaviour observed in the field. The main aim of this paper is to propose a simple methodology for characterizing the weathering behaviour of carbonate lithologies that outcrop in heterogeneous rock masses (such as Flysch slopes), for use by practitioners. To this end, the Potential Degradation Index (PDI) is proposed. This is calculated using the fragment size distribution curves taken from material retained in the drum after each cycle of the slake durability test. The number of slaking cycles has also been increased to five. Through laboratory testing of 117 samples of carbonate rocks, extracted from strata in selected slopes, 6 different rock types were established based on their slaking
\end{abstract}

M. Cano

miguel.cano@ua.es

R. Tomás

roberto.tomas@ua.es

1 Departamento de Ingeniería Civil, Escuela Politécnica Superior, Universidad de Alicante, PO Box 99, 03080 Alicante, Spain behaviour, and corresponding to the different weathering behaviours observed in the field.

Keywords Potential degradation index - Slake durability test · Fragment size distribution · Carbonate heterogeneous rock masses - Weathering behaviour

\section{Introduction}

In heterogeneous slopes, degradation mechanisms (and the choice of subsequent remedial works to be adopted) are closely linked to the weathering behaviour of the different lithologies which make up the slope. In these slopes, instabilities resulting from differential erosion/degradation are common (Cano and Tomás 2013a, b). This is of most importance in areas with an abrupt topography, where any linear works result in numerous cuttings and slopes. Throughout the service life of a transportation corridor, or any other asset whose construction results in the creation of slopes which are permanently exposed to the atmosphere, these instabilities result in significant maintenance and repair costs, and may pose a significant safety hazard. In the most extreme cases, these processes may trigger the failure of the entire slope, either suddenly or gradually. Additionally, these degradation processes may often be considered as failure mechanisms in their own right, rather than just triggering factors. Thus, the problem of slope stability over time should also be considered, where protection against weathering processes cannot be guaranteed (Mišccevic and Vlastelica 2014).

The phenomenon of slaking consists of the disintegration of clay-bearing rocks due to their interaction with water, which is common when they are exposed to the atmosphere. In areas whose climate is characterised by the 
absence of frosts and high temperature gradients, the weathering of the different lithologies is mainly caused by drying-wetting cycles due to rainfall and atmospheric moisture, meaning that in these areas the study of slaking is intrinsically linked to weathering behaviour. The study area, located on the Mediterranean coast of Alicante, precipitation is scarce, irregular and random. The summer drought extends from three to 5 months, with few rainy days. At the end of this period, the autumnal heavy downpours cause numerous episodes of flooding. Cloudiness and fog is also scarce, so the number of clear days is very high, with nearly $2900 \mathrm{~h}$ of annual sunlight. The annual average temperature is $18.3{ }^{\circ} \mathrm{C}$ and there is practically no meteorological winter (AEMET 2012, Table 1). The potential evapotranspiration is high, with a Thornthwaite index of $896 \mathrm{~mm}$, so there is a strong water deficit during most of the year (INGEMISA and Auernheimer 1991).

Resistance to slaking depends on many different parameters, commonly cited in the literature as; permeability, porosity, adsorption, mineralogy, microscopic texture, microfabric, presence of microfractures, etc. (Gamble 1971; Franklin and Chandra 1972; Richardson and Long 1987; Taylor 1988; Dick et al. 1994; Dick and Shakoor 1995; Martínez-Bofill et al. 2004; Erguler and Ulusay 2009; Kaufhold et al. 2013; Gautam and Shakoor 2015; Cano and Tomás 2015). This makes the characterization of slaking behaviour in rocks using a single parameter extremely complex (Erguler and Ulusay 2009; Gautam and Shakoor 2015).
The slaking susceptibility of clay-bearing rocks is known to influence the stability of heterogeneous slopes, as it may result in differential erosion/degradation. However, not all of these rocks show the same behaviour. Considerable differences in the manner of degradation and time taken to degrade may be observed. For this reason, it is extremely important to link behaviour quantified in the laboratory to that observed in the field, for example, using weathering patterns and weathering profiles (Cano and Tomás 2015).

Different rock masses show a specific response to each particular combination of weathering-related parameters present in situ, and the intensity and rate of this response determines its susceptibility to weathering, as described by Hack (1998). Results obtained using indices derived from Slake tests are generally useful for predicting the performance of different types of rocks qualitatively, although their use for the prediction of quantitative behaviour in field conditions is extremely questionable. However, correlations between slake durability and field performance do exist, as observed by Dick and Shakoor (1995) and Shakoor (1995). In addition, Hack (1998), Hack and Huisman (2002) and Nicholson (2001) have demonstrated that laboratory tests have severe limitations in predicting in situ rock mass performance, especially when discontinuities influence the rock mass behaviour. This should be taken into account when using indices obtained in a laboratory environment.

The Slake Durability test (Franklin and Chandra 1972) is the most widely used test worldwide for determining the

Table 1 Normal climatic values of Alicante from 1981 to 2010, AEMET (2012)

\begin{tabular}{lccccccccccc}
\hline Month & $T\left({ }^{\circ} \mathrm{C}\right)$ & $\mathrm{TM}\left({ }^{\circ} \mathrm{C}\right)$ & $\mathrm{Tm}\left({ }^{\circ} \mathrm{C}\right)$ & $R(\mathrm{~mm})$ & $\mathrm{RM}(\mathrm{mm})$ & $\mathrm{Rm}(\mathrm{mm})$ & $\mathrm{RMd}(\mathrm{mm})$ & $H(\%)$ & $\mathrm{DR}$ & $\mathrm{DF}$ & $I$ \\
\hline January & 11.7 & 17.0 & 6.3 & 22.8 & 82.0 & 0.0 & 54.8 & 67 & 3.6 & 0.4 & 181.2 \\
February & 12.3 & 17.6 & 7.1 & 22.1 & 95.1 & 0.0 & 40.5 & 66 & 3.0 & 0.3 & 180.3 \\
March & 14.2 & 19.6 & 8.9 & 23.0 & 79.7 & 0.2 & 32.8 & 65 & 3.4 & 0.0 & 226.9 \\
April & 16.1 & 21.3 & 10.9 & 28.7 & 91.7 & 1.2 & 40.8 & 63 & 4.1 & 0.0 & 247.0 \\
May & 19.1 & 24.1 & 14.1 & 27.8 & 88.7 & 0.0 & 42.1 & 64 & 4.0 & 0.0 & 277.4 \\
June & 22.9 & 27.8 & 18.1 & 11.9 & 56.8 & 0.0 & 45.1 & 63 & 1.8 & 0.0 & 302.3 \\
Juliet & 25.5 & 30.3 & 20.7 & 3.8 & 41.3 & 0.0 & 27.5 & 65 & 0.6 & 0.0 & 330.1 \\
August & 26.0 & 30.8 & 21.2 & 6.8 & 39.5 & 0.0 & 36.4 & 67 & 1.1 & 0.0 & 303.9 \\
September & 23.5 & 28.5 & 18.5 & 55.5 & 309.3 & $\mathrm{Imperceptible}$ & 270.2 & 69 & 3.3 & 0.0 & 249.9 \\
October & 19.7 & 24.9 & 14.5 & 47.4 & 271.1 & 0.1 & 220.2 & 70 & 4.5 & 0.0 & 216.7 \\
November & 15.4 & 20.5 & 10.3 & 35.9 & 117.0 & 0.0 & 68.3 & 69 & 4.2 & 0.0 & 173.4 \\
December & 12.6 & 17.7 & 7.4 & 25.4 & 170.9 & 0.6 & 119.8 & 68 & 3.8 & 0.1 & 163.8 \\
Year & 18.3 & 23.3 & 13.2 & 311.1 & 653.1 & 108.9 & 270.2 & 66 & 37.5 & 0.9 & 2850.9
\end{tabular}

$T$ monthly/annual average temperature, TM monthly/annual average of daily maximum temperature, Tm monthly/annual average of daily minimum temperature, $R=$ monthly/annual average rainfall, $R M$ monthly/annual maximum rainfall, $R m$ monthly/annual minimum rainfall, $R M d$ monthly/annual daily maximum rainfall, $H$ average relative moisture, $D R$ monthly/annual average days with rainfall higher to 1 mm, $D F$ monthly/annual average of frosty days, $I$ monthly/annual average hours of sunlight 
relationship between slaking and rock durability. This importance is underlined by its endorsement by the International Society for Rock Mechanics (ISRM 1981). Subsequently, the method was standardized by the American Society for Testing and Materials (American Society for testing and Materials (ASTM) 2004), where the second cycle index $\left(\mathrm{Id}_{2}\right)$ is denominated the Slake Durability Index, and used to quantify a rock's susceptibility to slaking. However, the test has numerous disadvantages, which will be discussed in subsequent sections of this paper.

The main aim of this paper is to propose a method for characterizing the weathering behaviour of carbonate lithologies that outcrop in heterogeneous Flysch-like slopes. The aim of the authors is that the method should be simple enough to be easily used in practice. This will be achieved by analysing the changes in the fragment size distribution of the material retained in the drum during the Slake Durability Test (ASTM 2004). This is important, as the test occasionally does not differentiate between rocks with different slaking behaviour, as it only measures the mass of particles smaller than $2 \mathrm{~mm}$ lost after each test cycle. This means that any particle larger than $2 \mathrm{~mm}$ is retained in the drum, and hence used to calculate the Id index. However, in some cases particles smaller than $2 \mathrm{~mm}$ make up a very small percentage of the overall sample mass, but the fraction of the initial sample that is retained in the drum disintegrates into numerous smaller particles. The result is that the Id indices do not correlate with the observed in situ durability.

Erguler and Shakoor (2009) proposed a new method to quantify the nature of rocks. This method quantifies the fragment size distribution of the slaked material, using a "disintegration ratio" calculated for each slaking cycle. This is defined as the ratio between the area under the fragment size distribution curve and the total area encompassing the entire range of the fragment size distribution. Erguler and Ulusay (2009) also suggested a disintegration index that can minimize some of the limitations of slake durability test. The comparison between the disintegration index values measured in the laboratory specimens and those in samples from the same outcrops, exposed to atmospheric conditions for 1 year, showed close agreement. Gautam and Shakoor (2013) proposed a method in which a "disintegration ratio" parameter was calculated from the fragment size distribution curves obtained from samples prepared in a similar manner to those used in the slake durability test, but exposed to natural climatic conditions for 1 year. Subsequently, the same authors (Gautam and Shakoor 2015) compared the laboratory slaking behaviour of common clay-bearing rocks to their slaking behaviour under natural climatic conditions observed during the aforementioned 1-year experimental study. In both studies the same "disintegration ratio" was used.

Similar to the aforementioned studies, this paper aims to evaluate the degradation potential of a sample by analysing changes in the fragment size distribution curves obtained from the material retained in the drum after each slake durability test cycle, up to a total of five cycles. This means that changes in the type, morphology and number of fragments are accounted for. As such, a single parameter for characterizing slaking behaviour is proposed, and the behaviour observed in the laboratory is compared with that observed in the field, under natural climatic conditions.

The study area chosen is situated in Southeastern Spain, in the coastal area of the province of Alicante (Fig. 1). From this area, 117 samples were taken, representative of the different carbonate Flysch lithologies present in Alicante. The area has a very abrupt topography, with a high population density and three main transportation corridors, which pass through the Flysch belt. This has resulted in a large number of cuttings, which show a range of instabilities related to the differential degradation of the different lithologies present.

\section{Lithological Setting of the Study Area}

\subsection{General Framework}

The Alicante Flysch sequence (Fig. 1) is composed of pelagic sediments, predominated by sequences of grey marls and thin white marly limestones (hemipelagites) that constitute the rythmite predominated by marls. This sequence may overlap calcarenitic turbiditic episodes. However, the sedimentological complexity of the Flysch formation is even greater because some superposed composite gravitational processes such as mélanges and debrites are also present (Cano and Tomás 2013a).

In this study, five slopes were selected and fully characterized (Fig. 1). 117 intact rock samples were extracted from all of the strata present in the selected slopes and were described in detail in the field. They were geologically classified as: (a) thick bedding calcarenites [Grainstone of turbiditic facies of channel (Ta-b)]; (b) thick bedding calcarenites [grainstone of turbiditic facies of channel (Ta-b) or sheet flood facies (Tb, Tb-c)]; (c) Thin bedding calcarenites [turbiditic thin beds of fan fringe facies (Tb-c-d)]; (d) poorly cemented thin bedding calcarenites [turbiditic thin beds of fan fringe facies (Tb-c-d)]; (e) slightly marly limestones; (f) marly limestones; (g) silty calcareous marls; (h) silty marls; (i) calcareous marls-marls; (j) sheet silty marls; (k) soft marls; (l) sheet marls; (m) soft calcareous mélanges; and (n) calcareous debrites. 


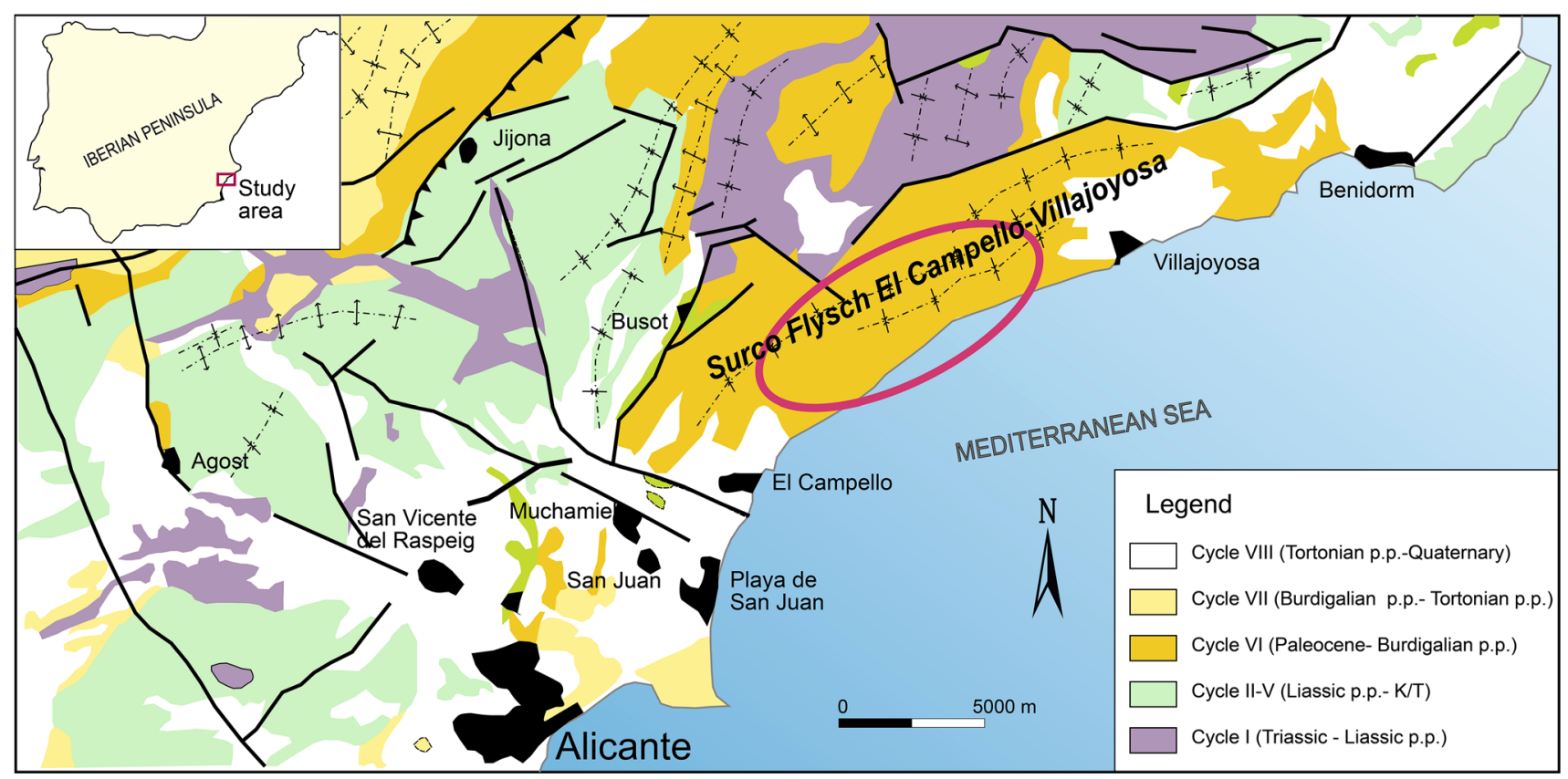

Fig. 1 Location and geological sketch maps of the study area [based on Vera (2004) in Guerrera et al. (2006)]. The ellipse indicates the location of the rock exposures in this study

\subsection{Characterization of Rock Mass Jointing}

At regional level, the area is fractured into several blocks linked to several main dextran fault systems, such as the Cadiz-Alicante fault (N70E), which generated N20E oriented folding, the Vinalopo fault system (N155E) and the Socovos fault system (N120E) that generated N70E oriented folding (Guerrera et al. 2006).

At local scale, six sets of discontinuities were observed in the slopes in the study, five of which are of tectonic origin (J1-J5). The sixth set corresponds to bedding. These five tectonic joints present a quasi-perpendicular disposition to the bedding, generating prismatic blocks with a variety of sizes and shapes for the different lithologies (Fig. 2a).

The two first sets $(\mathbf{J} 1, \mathrm{~J} 2)$ exhibit a very large persistence $(>20 \mathrm{~m})$, and the isolated blocks present a parallelepiped shape. Their average spacings are 28 and $18 \mathrm{~cm}$, respectively. $\mathrm{J} 3$ and $\mathrm{J} 4$ present a much lower persistence (1.4 and $2.2 \mathrm{~m}$, respectively) and average spacings of 47 and $25 \mathrm{~cm}$, respectively. J5 presents short to very short persistence $(1.1 \mathrm{~m})$ and $60 \mathrm{~cm}$ of average spacing.

The sixth set of discontinuities corresponds to bedding, which shows a very large persistence. As the studied slopes are heterogeneous, the bedding has been specifically described for each of the lithologies outcropping in the study area. Typically, the thick bedding calcarenites units are $25-120 \mathrm{~cm}$ thick and the bedding spacing is $7-30 \mathrm{~cm}$. They are thick bedded blocky, consisting of tabular blocks formed by two to five other intersecting discontinuity sets. The size and shape of these blocks is different to other, less competent lithologies. This is because some discontinuities are well cemented, behaving as if there were no such discontinuity. The slightly marly limestones units are $12-60 \mathrm{~cm}$ thick, the bedding spacing is $10-30 \mathrm{~cm}$ and they are prismatic blocky. The calcareous mélange units are 50-200 cm thick and exhibit a chaotic structure with a high erratic discontinuity surfaces density that results in heterometric rock blocks (centimetric to decimetric) with different morphologies. The thin bedding calcarenites (C) units are $5-20 \mathrm{~cm}$ thick, the bedding spacing is $3-10 \mathrm{~cm}$ and they are very blocky with prismatic shape. The thin bedding calcarenites $(\mathrm{L})$ units are $5-30 \mathrm{~cm}$ thick and the bedding spacing is $3-10 \mathrm{~cm}$. They are thin bedded blocky consisting of parallelepipedic blocks. The only observed unit of calcareous debrites in the studied slopes is $600 \mathrm{~cm}$ thick and exhibits a chaotic structure constituted by blocks and a calcareous matrix with a high erratic discontinuity surfaces density that generates heterometric rock blocks (centimetric to decametric block size) with different morphologies. The only unit of soft calcareous mélange encountered is $20 \mathrm{~cm}$ thick and has a chaotic structure. Thin bedding silty calcarenites units are $2-50 \mathrm{~cm}$ thick, the bedding spacing is $2-10 \mathrm{~cm}$. They are thin bedded blocky consisting of parallelepipedic blocks. The marly limestones units are $10-80 \mathrm{~cm}$ thick and the bedding spacing is $8-30 \mathrm{~cm}$. They are very blocky with prismatic shape, in the same manner as the other lithologies listed below. The silty 

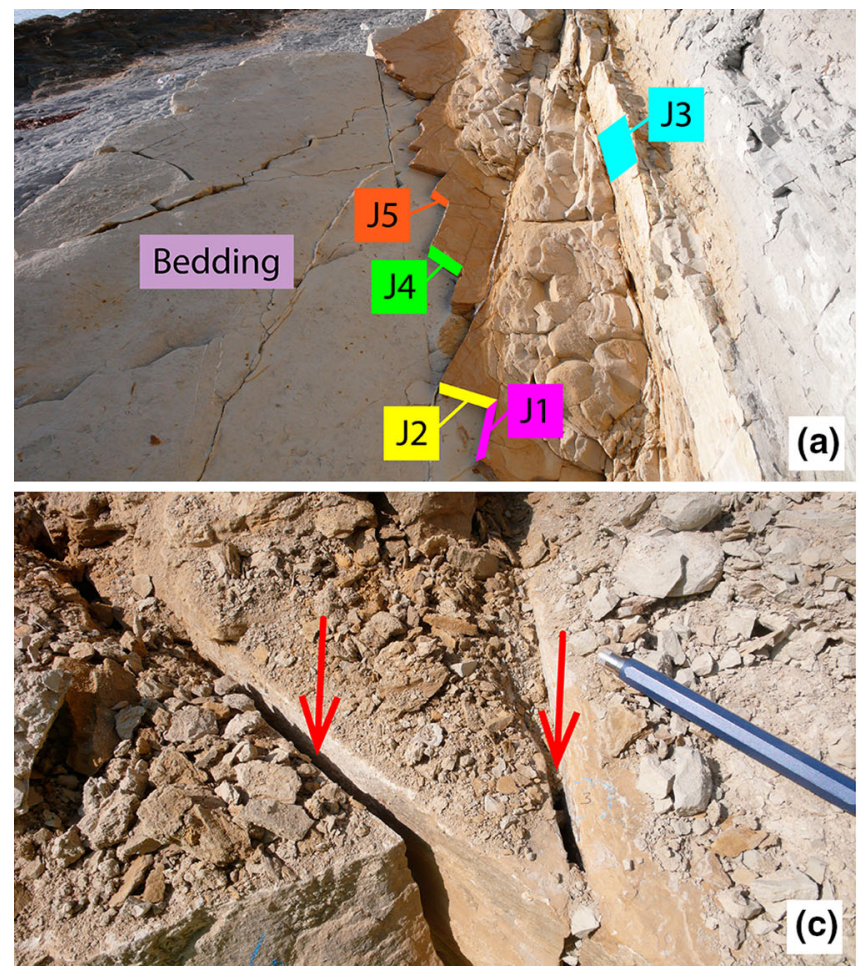

Fig. 2 a Plan view of a slope in this study, in which the different discontinuity sets are recognized. b Different aperture and infilling cases from the most carbonate lithologies: 1 opening of $4 \mathrm{~mm}$ partially filled of calcite, 2 joint of $1 \mathrm{~mm}$ partially filled, 3 joint with $1.5 \mathrm{~mm}$ of calcite infilling width, 4 joint of $0.5 \mathrm{~mm}$ of calcite infilling

calcareous marls units are $15-50 \mathrm{~cm}$ thick and the bedding spacing is $8-15 \mathrm{~cm}$. The silty marls units are $20-70 \mathrm{~cm}$ thick and the bedding spacing is $10-14 \mathrm{~cm}$. The calcareous marls-marls units are $15-160 \mathrm{~cm}$ thick and the bedding spacing is $9-30 \mathrm{~cm}$. The sheet silty marls units are $30-160 \mathrm{~cm}$ thick and the bedding spacing is $10-23 \mathrm{~cm}$. Soft marls are $25-40 \mathrm{~cm}$ thick and the bedding spacing is $10-15 \mathrm{~cm}$

Regarding openings, it should be noted that in the studied rock masses the presence of infilling in the openings of discontinuities, which are extension joints (not veins), highly depends on the lithology of the unit. As such, only in the following lithologies, which showed high contents of carbonate, are discontinuities filled by free crystals of calcite: thick bedding calcarenites, slightly marly limestones, calcareous mélange, thin bedding calcarenites (C), calcareous debrites, marly limestones, silty calcareous marls and soft calcareous mélange. In these carbonatic lithologies, the opening of joint $\mathrm{J} 1$ varies between 0.5 and $10 \mathrm{~mm}$ and is completely or partially filled by calcite. The width of $\mathrm{J} 2$ ranges from very tight $(<0.1 \mathrm{~mm})$ to open $(1 \mathrm{~mm})$ and the filling is also made of calcite that can partially fill the discontinuity space or even not be present, leading to a partially open to open
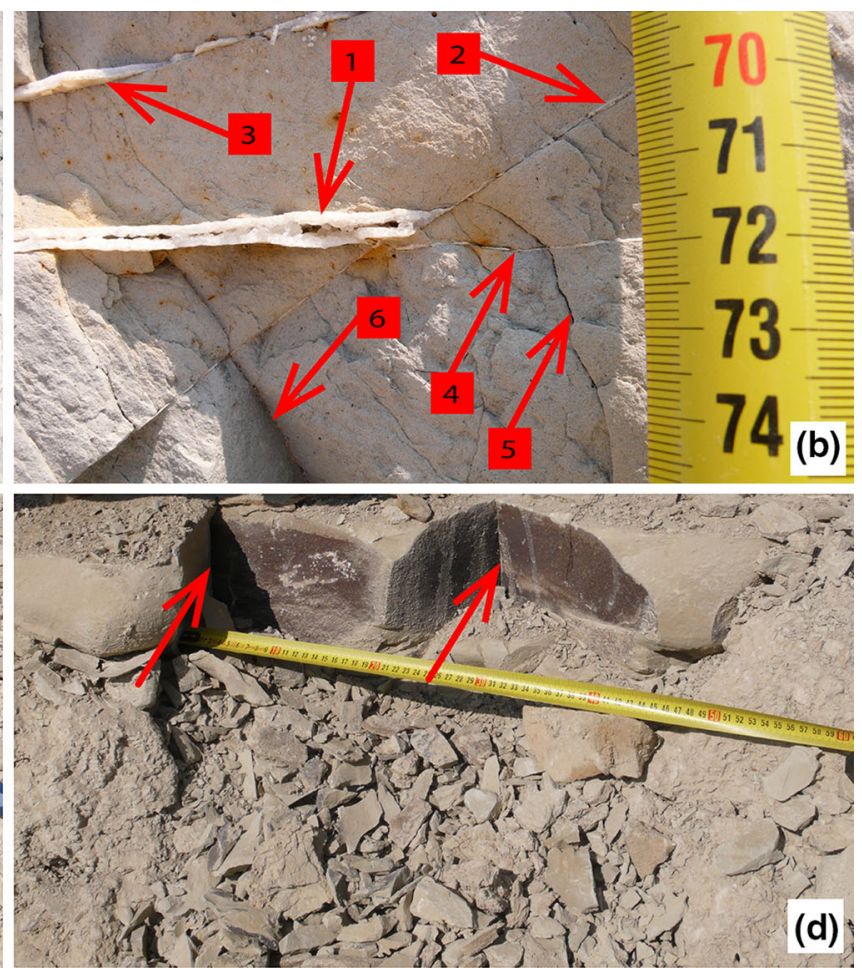

width, 5 joint with an aperture of $0.5 \mathrm{~mm}$, without filling, 6 joint very tight $(<0.1 \mathrm{~mm})$. c Appearance of a set of thick bedding calcarenites with dislocated blocks because of mechanical excavation. d Appearance of a set of calcareous marls-marls with interlocked blocks. Mechanical excavation has not affected these discontinuities

discontinuity. Opening ranges are from 0.5 to $5 \mathrm{~mm}$ for $\mathrm{J} 3$ and from 0.1 to $3 \mathrm{~mm}$ for $\mathrm{J} 4$. In both cases, the joint is filled or partially filled by calcite. J5 exhibits 1 to $3 \mathrm{~mm}$ calcite infilling width (Fig. 2b). Otherwise, in the marly lithologies, the discontinuities also present an aperture varying between $<0.1 \mathrm{~mm}$ to $10 \mathrm{~mm}$, but without calcite infill. Finally, the joints that correspond to bedding are mainly very tight or they are cemented in the more calcareous lithologies. Additionally, a patina of iron oxide and manganese oxide species in dendritic form has been commonly observed in all sets of discontinuities, including bedding.

Both intact rock and discontinuities exhibited a weathered state, from the face of the slope to certain depth. The degree of alteration changed according to the lithology and the depth, according to Cano and Tomás (2015).

Generally, both, the tectonic discontinuities and the bedding are planar, mainly rough or sometimes slightly rough in the more carbonatic lithologies and smooth or slightly rough in the marly lithologies. Occasionally, the tectonic discontinuities of the units of thick bedding calcarenites, mainly the thickest ones, show evidence of karstification, which generates more undulated or stepped, and very rough joints, and also greater apertures $(20 \mathrm{~mm})$. 
Occasionally, the bedding surface presents load casts at the bottom of calcarenite units of metric thickness at the contact with marly lithologies, generating very rough joints with large undulation. Sometimes, the bedding presents slickensided surfaces.

Water flow was not observed, although after downpours the discontinuities and the intact rock of marly lithologies were wet.

The effect of the excavation method on the disturbance of a rock mass is a well-known phenomenon (Romana 1993; Hoek et al. 2002). However, a large number of factors can influence the degree of disturbance in the rock mass surrounding an excavation, and it may never be possible to quantify these factors precisely (Hoek et al. 2002). Four of the five studied slopes were excavated using mechanical methods and the fifth slope is a natural hill. Due to the heterogeneous nature of these slopes, when the cuts are excavated by means of mechanical methods, the low competence lithologies (e.g., soft marls, silty marls, etc.) are sheared through the rock matrix. However, in the high competence sets (e.g., thick bedding calcarenites) the blocks are broken off through their discontinuities, dislocating them towards the slope face. This is the reason why in the slope face of these sets, the aperture of the discontinuities is higher than that observed in the inner part of the slope, in which the blocks have not been perturbed by the mechanical action of the excavation (Fig. 2c, d). Another cause of the greater discontinuity opening in the more competent blocks from the slope face is the dislocation of rock blocks due to removing underlying unit effects of erosion and/or differential degradation.

\section{Methodology}

\subsection{General Overview}

The main aim of this paper is to characterize the slaking behaviour of the different carbonate lithologies outcropping in the study area, to aid the prediction of their weathering behaviour following the excavation of a slope or cutting. To this end, the different lithologies were identified and described in the field and their mineralogical characteristics obtained. 5-cycle slake durability tests were performed on intact rock samples. Fragment size distribution curves were also obtained and their morphology analysed. A modified parameter $\left(D_{\mathrm{RP}}\right)$ based on the original "disintegration ratio" $\left(D_{\mathrm{R}}\right)$ proposed by Erguler and Shakoor (2009), has also been proposed. From $D_{\mathrm{RP}}$, a novel parameter named potential disintegration index (PDI) based on the change in the $D_{\mathrm{RP}}$ ratio between slake cycles has been defined. The combined use of the PDI, together with the analysis of the shape of the particle size distribution curves, and the behaviour of retained fragments throughout the five cycles of the slake durability test (changes in size and shape) has allowed a new classification of the slake behaviour of these lithologies to be proposed. Additionally, the proposed slake behaviour classes were compared with the weathering patterns and weathering profiles observed in the same lithologies in the field (Cano and Tomás 2015) (Fig. 3). The methodology used in this study is described in the following paragraphs.

\subsection{Intact Rock Mineralogy}

In this study, the different lithologies were described in the field using a simplified geological classification of rocks based on their genetic classification, structure, composition and grain size (Geological Society of London 1977). Additionally, a mineralogical characterization of the samples by X-ray diffraction was performed. Because some of the samples were of marly composition, they were characterized in two different stages. Firstly, X-ray diffractograms of all the samples were obtained. Secondly, X-ray diffractograms of the oriented aggregate of samples with high phyllosilicate content were obtained, to identify them according to Robert and Tessier's (1974) methodology. Finally, for some representative samples, the carbonate contents obtained from the interpretation of the X-ray diffractograms were compared with those obtained using the Bernard calcimeter test (ASTM 2007a), to validate these results.

Data were collected and interpreted using the XPowder software package, (Martin 2004) whose qualitative searchmatching procedure was based on the ICDD-PDF2 database.

\subsection{Assessment of Fragment Size Distributions After the Slake Durability Test}

The Slake Durability Test (SDT) is one of the simplest tests in rock mechanics, and is the most widely used test worldwide for characterizing the environmental weathering resistance of rock. Although originally the slake durability test was developed for testing the weathering potential of shales, mudstones, siltstones, and other clay-bearing rocks (Franklin and Chandra 1972), the slake durability index is also typically used for testing weak rocks such as mudstones, marls, ignimbrites, conglomerates, and poorly cemented sandstones (Sabatakakis et al. 1993; Santi 1998; Czerewko and Crips 2001; Erguler and Ulusay 2009; Miščcević and Vlastelica 2011). Consequently, although in the Flysch formation there are some very competent, hard turbiditic rocks that show very high durability indices, to classify the Flysch lithologies using a uniform weathering 


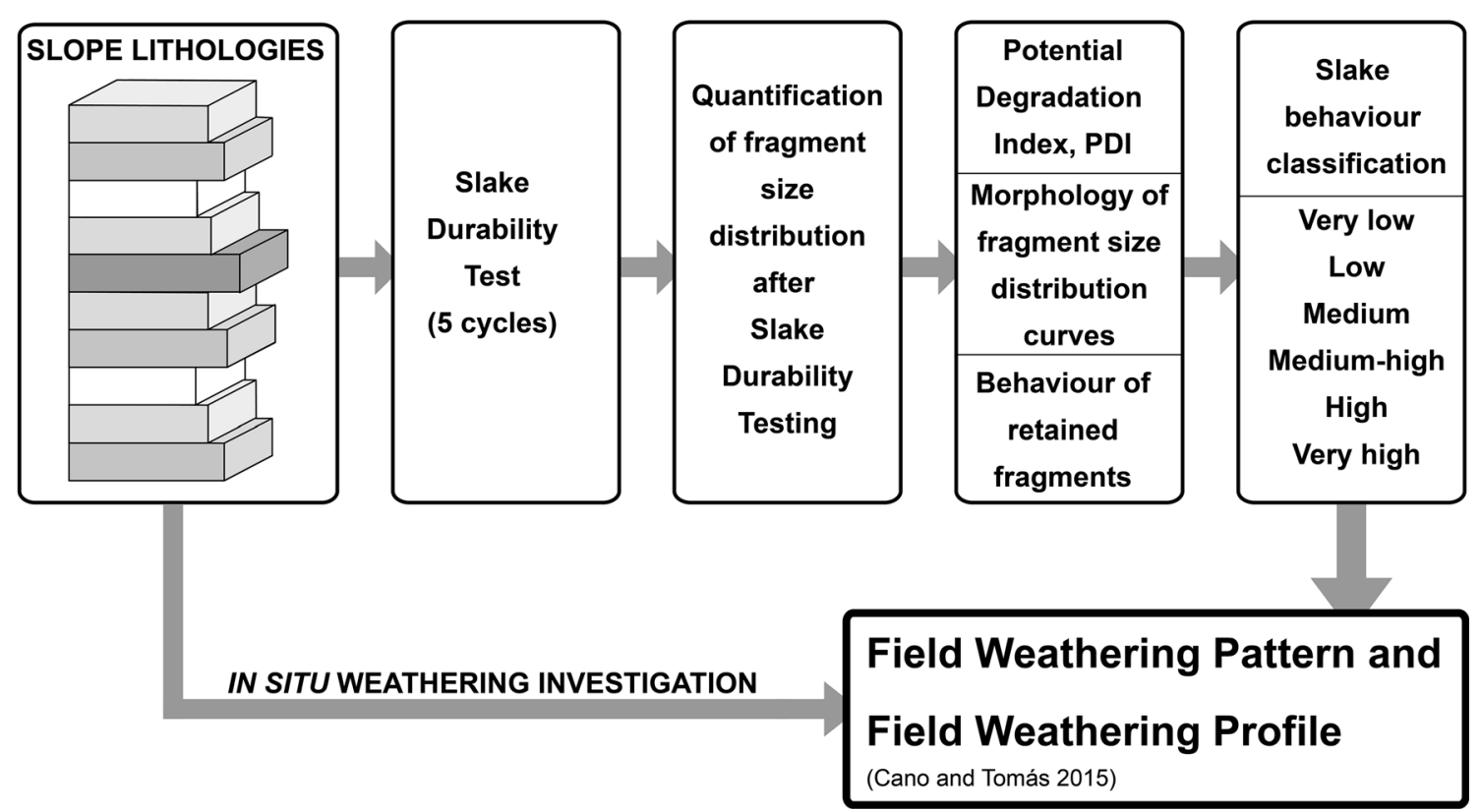

Fig. 3 Conceptual sketch of the slaking and weathering characterization of the Flysch lithologies

potential criteria, the slake durability test was used for testing all of the samples.

The durability of weak rocks is usually assessed using the second-cycle slake durability index $\left(\operatorname{Id}_{2}\right)$. Nevertheless, some authors (Gamble 1971; Taylor 1988; Moon and Beattie 1995; Ulusay et al. 1995; Bell et al. 1997; Gökçeoğlu et al. 2000; Erguler and Shakoor 2009; Miščcević and Vlastelica 2011) have suggested that index values taken after three or more cycles of slaking and drying may be useful when evaluating higher durability rocks, such as those in this study.

As part of a previous study, it was observed that within the study area some intact rock samples showed high Id1 and Id2 indices [after Franklin and Chandra (1972) and Gamble (1971)], in contrast with the weathering behaviour observed in situ. As such, it was concluded that the observed weathering of the rocks was much higher than that predicted by the SDT indices (Cano and Tomás 2015).

This appeared to be related to the fact that, despite the high $\mathrm{Id}_{2}$ values obtained, the sample retained in the drum was extremely fragmented and visually appeared highly degraded. However, the fragments were larger than $2 \mathrm{~mm}$, leading to the high $\mathrm{Id}_{2}$ values obtained (see Fig. 4).

The American Society for Testing and Materials requires that as part of the slake durability test, in addition to the $\mathrm{Id}_{2}$ index, the fragments retained in the drum should be qualitatively categorized as type I material (primarily large fragments), type II material (mixture of large and small fragments), or type III material (primarily small fragments) (American Society for testing and Materials (ASTM) 2004). However, Erguler and Shakoor (2009) demonstrated these categories are insufficiently detailed to give a refined classification. As a consequence, it is obvious that the $\mathrm{Id}_{2}$ index does not adequately reproduce the real degradation properties of the Flysch lithologies studied, providing optimistic values.

It should be noted that rock specimens found on superficial parts of slopes usually show signs of weathering or even severe degradation. As a consequence, the Flysch rock samples tested correspond to intact rocks that were obtained from the inner part of the slope. Subsequently, the intact rock samples were transported to the laboratory in plastic bags, and maintained at a constant temperature. The time between storage and testing was always less than 1 week. While the tests were performed, the laboratory temperature was also kept constant $\left(24 \pm 2{ }^{\circ} \mathrm{C}\right)$ to conserve humidity and temperature conditions.

The tests were performed according to the ASTM (2004), with five test cycles performed. Five cycles were chosen because of: (a) the need to compare hard and soft lithologies using the same parameter; (b) the existence of some durable rocks which are unaffected by a low number of cycles; (c) the need to study the rocks' long-term weathering behaviour; and (d) the need to avoid an excessively long test period.

It is unrealistic to classify carbonate Flysch lithologies according to their in situ weathering behaviour after longterm exposure to real conditions based solely on the indices obtained from the slake durability test. As such, many authors have combined (in various different ways) the results of the slake durability test with the analysis of particle size distribution curves (Erguler and Shakoor 


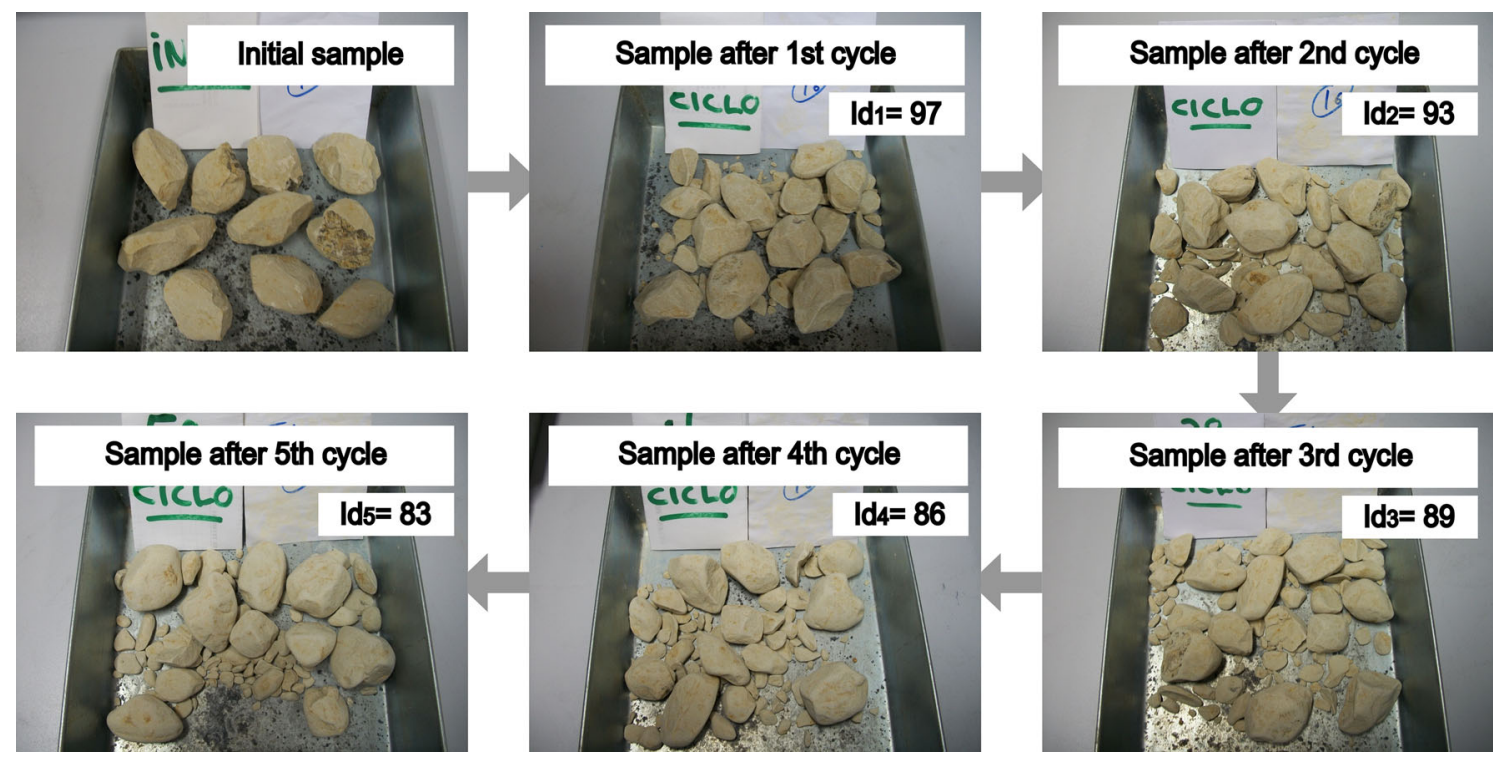

Fig. 4 Example of heavily degraded calcareous marls after successive cycles of slake durability test (SDT) with $\mathrm{Id}_{2}=93$. Note that two-cycle $\left(\mathrm{Id}_{2}\right)$ SDT results classify this sample as "high durability". The Id values calculated for each cycle are also shown

2009; Erguler and Ulusay 2009; Gautam and Shakoor 2013, 2015), with the aim of improving the characterization of various lithologies according to their weathering behaviour.

The procedure adopted as part of this study was as follows. Firstly, ten $40-60 \mathrm{~g}$ pieces of intact rock were taken from the study area, providing a total sample mass of $450-550 \mathrm{~g}$. The samples were dried for $24 \mathrm{~h}$ in an oven at $105{ }^{\circ} \mathrm{C}$, sieved, and immediately placed in the slake durability test apparatus. After the first test cycle, the sample retained in the drum was dried, sieved and weighed. This procedure was repeated for a further four cycles, giving a total number of five test cycles. The sieving procedure adopted for determining fragment size distribution curves was the same as that used for soils (ASTM 2007b), using standard sieves whose aperture sizes were 40, 31.5, $25,20,12.5,10,6.3,5$ and $2 \mathrm{~mm}$. The results were plotted in semi-logarithmic scale, to show the fragment size distribution of samples before and after each test cycle. The curves were plotted on the same graph, to easily observe changes in the samples after each slaking cycle. The sieve apertures used were shown on the $x$-axis in semi-logarithmic scale, and the percent passing (by weight) on the $y$ axis. It is important to note that the samples were sieved with extreme care, to avoid further fragmentation of the particles retained in the drum, which could have been mistakenly attributed to the effects of the previous slaking cycle.

Erguler and Shakoor (2009) proposed the disintegration ratio $\left(D_{\mathrm{R}}\right)$ parameter as the sole indicator of the effects of each slaking cycle on the fragment size distribution curves. It is defined as:
$D_{\mathrm{R}}=\frac{A_{\mathrm{C}}}{A_{\mathrm{T}}}$

where $A_{\mathrm{C}}$ is the area under any size distribution curve and $A_{\mathrm{T}}$ is the total area encompassing the whole range of fragment size distributions. In this study, a similar parameter is proposed. However, as the graphs used show percent passing (by weight), as opposed to percent retained (by weight), when the parameter is equal to $1\left(A_{\mathrm{C}}=A_{\mathrm{T}}\right)$ this represents the maximum degree of degradation possible. To avoid confusion, the proposed new parameter has been named $D_{\mathrm{RP}}$ (Fig. 5).

Despite the fact that $D_{\mathrm{RP}}$ can be a good indicator of the degradation potential of the weakest rocks, it has been observed that the size and shape of the fragments that are retained in the drum between cycles changes from one cycle to the next, throughout the five slaking cycles. This observation agrees well with in situ observations, where the form and visual condition of lithologies change over time. For this reason, it is proposed that the change in the calculated $D_{\mathrm{RP}}$ value between slaking cycles is evaluated. To this end, a logarithmic curve was fitted to the $D_{\mathrm{RP}}$ values obtained for each sample and the $R^{2}$ and typical error values were calculated (Fig. 6). From this curve, the number of cycles required for a sample to reach $50 \%$ of the maximum possible degradation $\left(D_{\mathrm{RP}}=1\right)$ could be estimated. This number of cycles is denominated $N_{50}$. In the example shown in Fig. 6, from the fitting equation:

$D_{\mathrm{RP}}=0.082 \mathrm{Ln}(\mathrm{Nr})+0.035$

The $\mathrm{Nr}$ value for $D_{\mathrm{RP}}=1$ is $\mathrm{Nr}=N_{50}=290$ cycles. However, owing to the fact that the slaking resistance of the rocks in the study varied greatly, the range of $N_{50}$ 
Fig. 5 Example showing the calculation of $D_{\mathrm{RP}}$ after each slaking cycle. In this case, after the first cycle $D_{\mathrm{RP}}(1)$

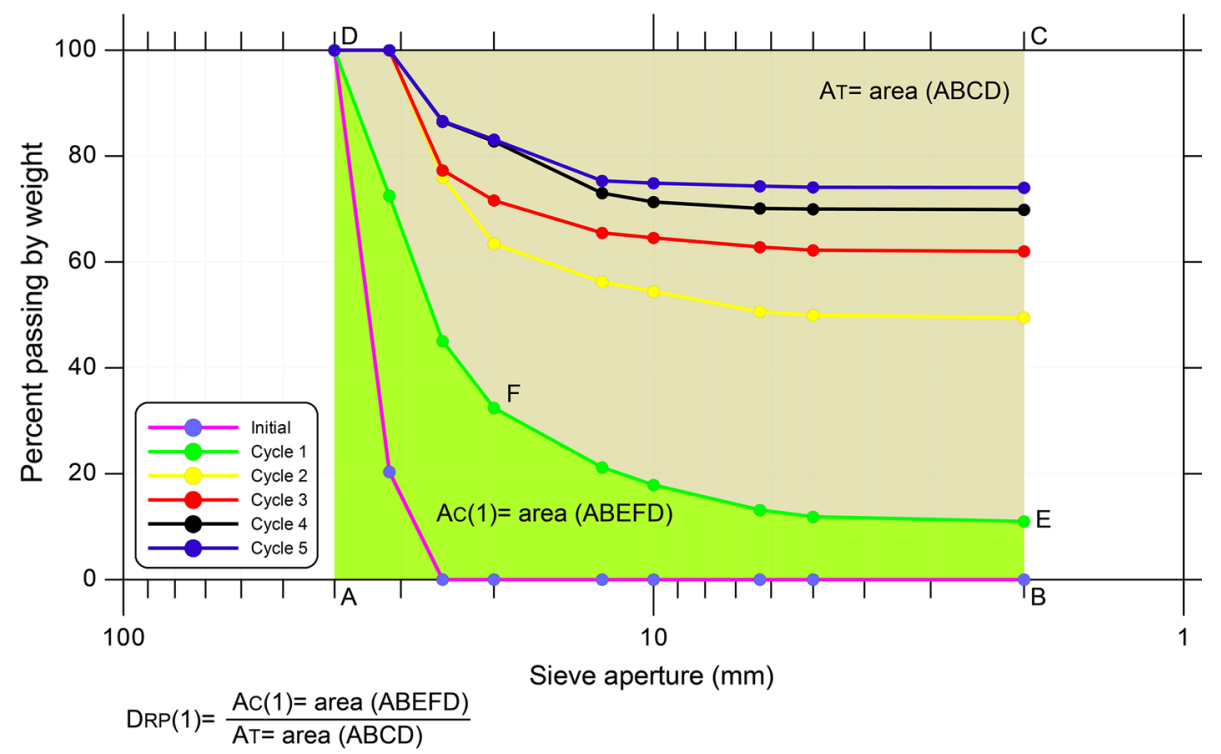

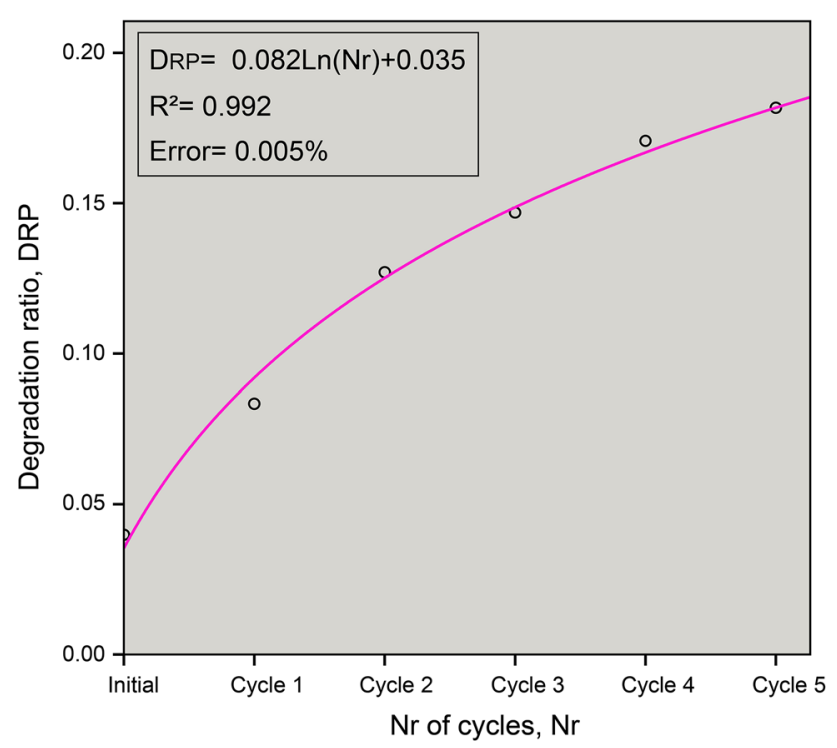

Fig. 6 Example of a logarithmic curve fitted to the plot of the $D_{\mathrm{RP}}$ parameter against slake durability test cycles, shown for the sample H15

values was very large, varying from $N_{50}=2$ in rocks that were very susceptible to degradation, to $N_{50}=8.10^{19}$ in rocks which were not. As such, a new parameter was defined to aid the classification of samples-the Potential Degradation Index (PDI). This is calculated as:

$\mathrm{PDI}=\operatorname{Ln} N_{50}$

The values calculated for the samples in this study vary from 0.8 to 46 , with a value of PDI $=5.7$ calculated for the example in Fig. 6.

As such, using only the Potential Degradation Index, the potential long-term degradation of a given sample from a carbonate lithology may be assessed. However, with the aim of refining the classification limits, to better distinguish between the numerous lithotypes present in the study area, a qualitative study was performed on the fragments retained in the drum during the different cycles of the slake durability test, and a classification was proposed. Three factors are proposed to standardize this classification: roundness, number of fragments, and fragment size (Table 2; Fig. 7).

Using these standard factors, 11 slaking behaviour patterns were defined based on the changes observed in the fragments. A distinction is made between three different textures present in the lithotypes: compact, laminated and poorly cemented (Table 3 ).

A qualitative analysis of the changes in morphology in the six fragment size distribution curves obtained for each sample after five slake durability test cycles was performed. The curves showing a similar morphology were grouped.

Using all of the aforementioned parameters (behaviour in terms of changes in the retained fragments, changes in the shape of the fragment size distribution curves, and principally the potential degradation index parameter), all of the samples taken as part of the study were classified, and limits between the different classes were established.

However, the procedure required for this classification was somewhat laborious. To improve ease of use, the changes in the morphology of the fragment size distribution curves throughout the five slaking cycles were analysed quantitatively, and a parameter which is simpler to obtain (but correlates well with the potential degradation index) was proposed. For the 117 samples in the study, parameters habitually used in sieve analysis in soil 
Table 2 Standardised qualitative factors used to describe the behaviour of the fragments retained in the drum throughout the five slaking cycles [adapted from ASTM (2004)]

Roundness
$R 2$ The edges of the fragments appear similar to before the test cycles, or show slightly blunted edges
may still be noted
$R 3$ The fragments show a rounded shape. The initial shape of the particle is not visible
Increasing The number of fragments increases significantly from one cycle to the next
Equal The number of fragments is largely constant from one cycle to the next. Small pieces occasionally break off
from the corners of the largest fragments and very occasionally a large fragment breaks into two medium sized
fragments
Reducing The number of fragments reduces significantly from one cycle to the next
Large fragments $(L)$ The entire sample is composed of large fragments, with occasional smaller fragments
Small fragments $(S)$ The sample is composed primarily of small fragments
Mixture of large and small fragments $(M)$ The sample is composed of a mixture of fragments of different sizes,
which may or may not be rounded

Fig. 7 Samples representative of the three standard factors which have been chosen to describe the behaviour of the fragments retained in the drum after each slaking cycle. $a 1, a 2$, and $a 3$ are examples of roundness types R1, R2 and R3. $b 1, b 2$ and $b 3$ show the different fragment sizes, corresponding to large (L), small (S) and a mixture (M) of fragments, respectively. $c 1, c 2$ and $c 3$ show the variation in number of fragments between two consecutive cycles-reducing, equal and increasing, respectively
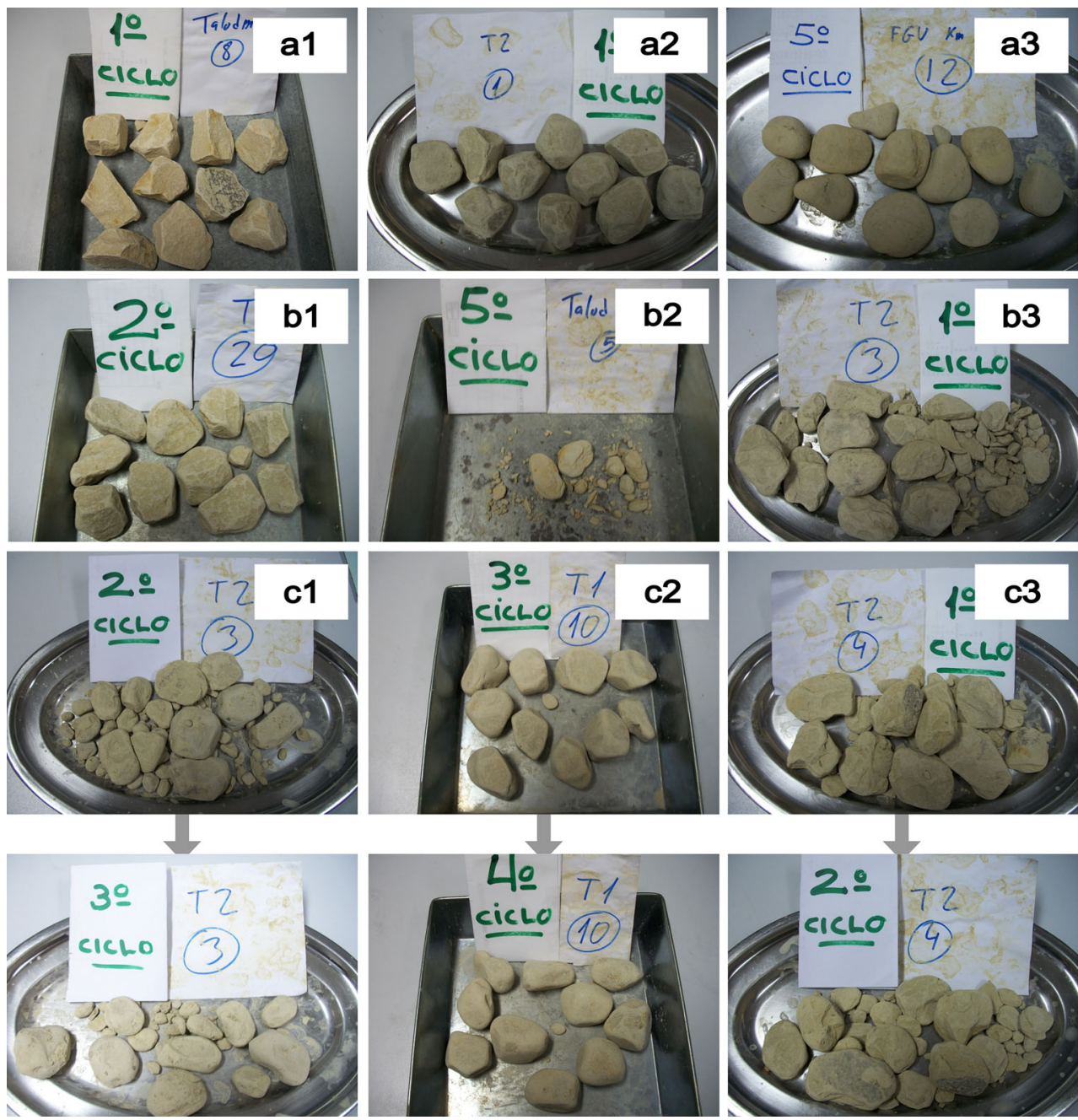

mechanics or sedimentology were calculated, such as the coefficient of uniformity $\left(C_{\mathrm{U}}\right)$, curvature coefficient $\left(C_{\mathrm{C}}\right)$, diameter for which $50 \%$ of the sample passes $\left(D_{50}\right)$, percentage of sample passing a certain sieve size, etc. as well as combinations of these parameters which described the shape of the fragment size distribution curves. Using 
Table 3 Slaking behaviour patterns based on changes observed in the fragments retained in the drum

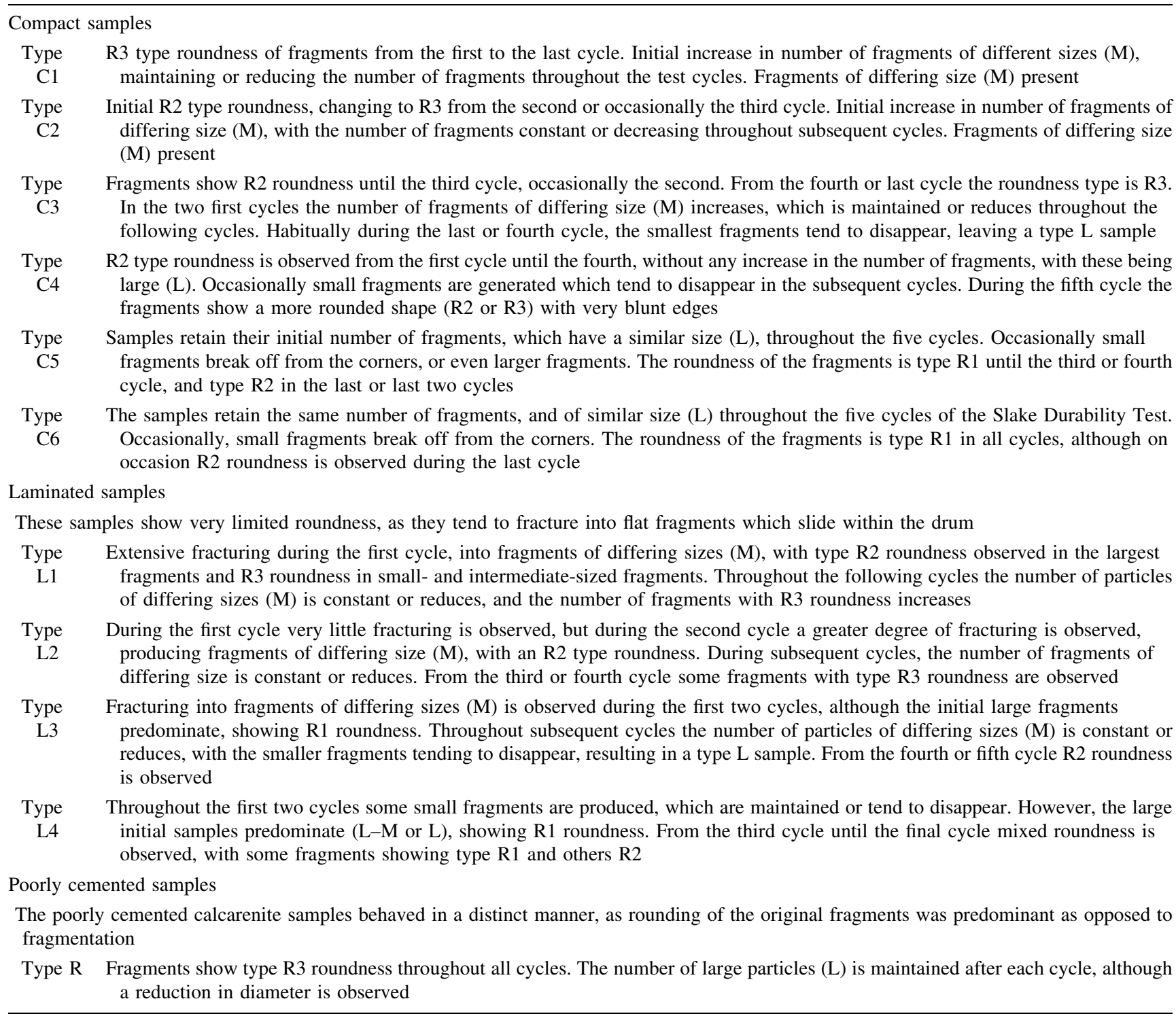

the IBM SPSS Statistics program, possible correlations between these parameters and the Potential Degradation Index were investigated, with the $R^{2}$ and typical error values calculated for each curvilinear approximation. The parameters that showed the best fit were the $D_{50}$ range (i.e. the variation between the initial $D_{50}$ and the value after the fifth slaking cycle) and the sample percentage passing through the $12.5 \mathrm{~mm}$ sieve $\left(\mathrm{P}_{12.5}\right)$. These parameters have the additional advantage of quantifying the changes in shape of the fragment size distribution curves (Fig. 8). Of these two parameters, the best correlation was given by $P_{12.5}$. The parameter also has the advantage of allowing the same number of classification groups to be established.

Once all of the samples were classified, the behaviour of the different lithotypes from which the samples were extracted was studied and compared with the weathering patterns and weathering profiles defined by Cano and Tomás (2015).

\section{Slake Behaviour Classification: Potential Degradation Index (PDI)}

As discussed in the previous section, changes in the $D_{\mathrm{RP}}$ parameter throughout the slake durability test cycles were evaluated for 117 samples (Fig. 6). The $R^{2}$ values and typical error were calculated for the logarithmic curves fitted to each sample. All of the curves showed a good fit, with an average $R^{2}$ value of $R^{2}=0.977 \pm 0.023$, and an error of $e=0.05 \%$. 
Fig. 8 Calculation of $D_{50}$ range and maximum percent of sample passing through the $12.5 \mathrm{~mm}$ sieve $\left(P_{12.5}\right)$. Note that the higher the $P_{12.5}$ and $D_{50}$ values the worst the slaking behaviour of the rock

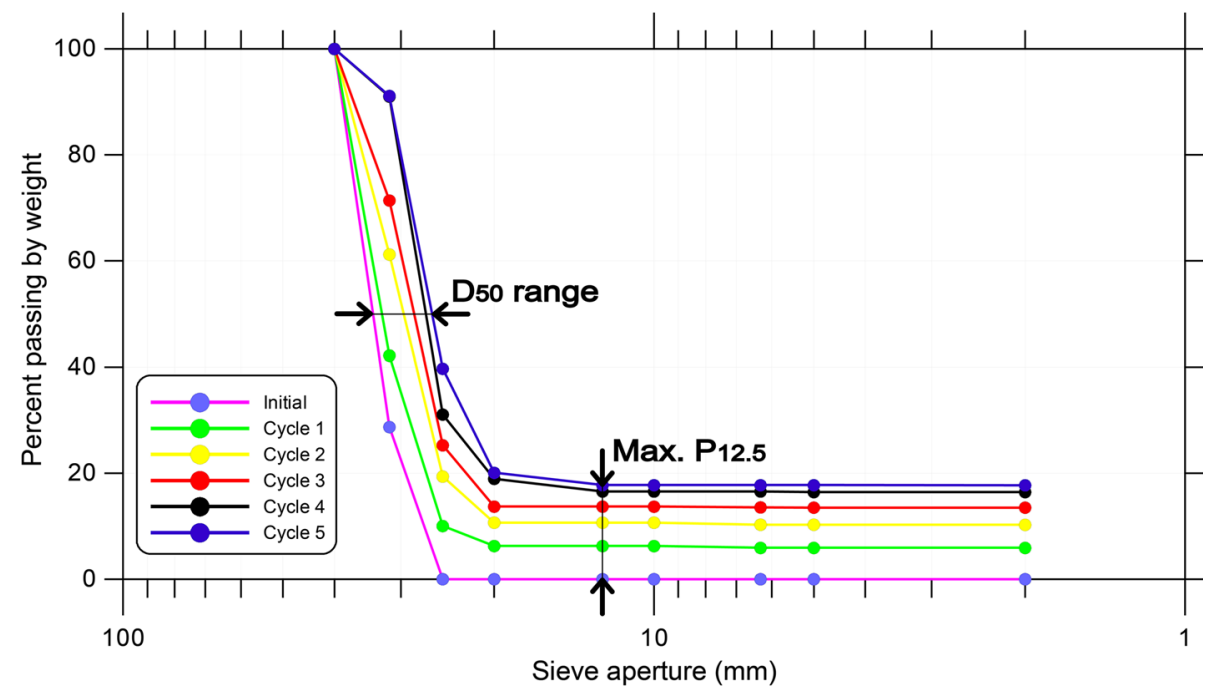

Using the curves fitted to each sample, the $N_{50}$ value for each was determined, and hence also the PDI parameter (as described in Sect. 3.3), which was used to classify the samples. Six durability classes were established: Very low, Low, Medium, Medium-high, High and Very high (Table 4), which correspond to a specific manner of degradation observed in the fragments retained in the drum (see Fig. 9).

Following qualitative analysis of the change in morphology of the six fragment size distribution curves obtained for each of the five slake durability test cycles, and aided by the quantification of these changes using the $D_{50}$ range, and maximum percent of sample passing through the $12.5 \mathrm{~mm}$ sieve $P_{12.5}$ (Fig. 7), similar fragment size distribution curves were grouped together into the same six categories used to group samples by their PDI parameter (Fig. 10).

The calculation of the PDI parameter, while not complex, is somewhat laborious. As such a parameter which is simpler to obtain, but which correlates well with the PDI, is proposed. This is the maximum percent of sample passing through the $12.5 \mathrm{~mm}$ sieve $\left(P_{12.5}\right.$, Fig. 8$)$, which can be fitted to the PDI using a power function (Fig. 11), and used to establish the boundaries of the same six classes (Table 4).

\section{Field Weathering Characterization}

The final part of this study consists of comparing the slaking behaviour of the different samples, based firstly on the analysis of changes in the fragments retained in the drum (see Tables 2, 3; Fig. 7), secondly on the calculation of the potential degradation index, and finally by attending to the weathering patterns and weathering profiles of the different lithologies, as observed in the field by the authors of this study. The field observations of the different lithologies were made for rock that had been exposed to natural climatic conditions over a long period of time. The weathering patterns are defined as follows [based on Cano and Tomás (2015)]:

Not weathered (NW); slight discoloration (A); reduction by arenization (B); flat weathering front peeling off (C); conchoidal peeling off (D); incipient rounding of blocks formed by tectonic joints (E); ellipsoidal morphology blocks formation (F); cubic centimetre fracturing of ellipsoidal block $(\mathrm{G})$; incipient conchoidal fracture of ellipsoidal blocks and formation of ellipsoidal blocks of minor size $(\mathrm{H})$; total conchoidal exfoliation of ellipsoidal blocks (I); massive fracturing in centimetric pseudocubic blocks $(\mathrm{J})$; residual soil $(\mathrm{K})$; centimetric rhomboidal fracturing in centimetric thickness strata (L); and massive fracturing of centimetric thickness strata $(\mathrm{M})$. The field weathering profile is comprised of the sum of different weathering patterns (e.g. FHIJK, EFG, etc.) and in the field it was observed that weathering profiles depended on the lithological nature of the strata, although some lithologies showed similar weathering profiles (Table 4).

\section{Results, Analysis and Discussion}

The proposed classification is based on the PDI, although to help define the limiting values for each class, the changes in shape of the fragment size distribution curves were also used. Additionally, the $P_{12.5}$ parameter correlated very well with the PDI, and is less laborious to obtain. As such, this parameter is proposed as an alternative to be used by practitioners.

In addition, the behaviour of the fragments retained in the drum throughout the slaking cycles was studied for each of the 117 samples. As commented previously, this behaviour varied depending on whether the samples showed a compact, 


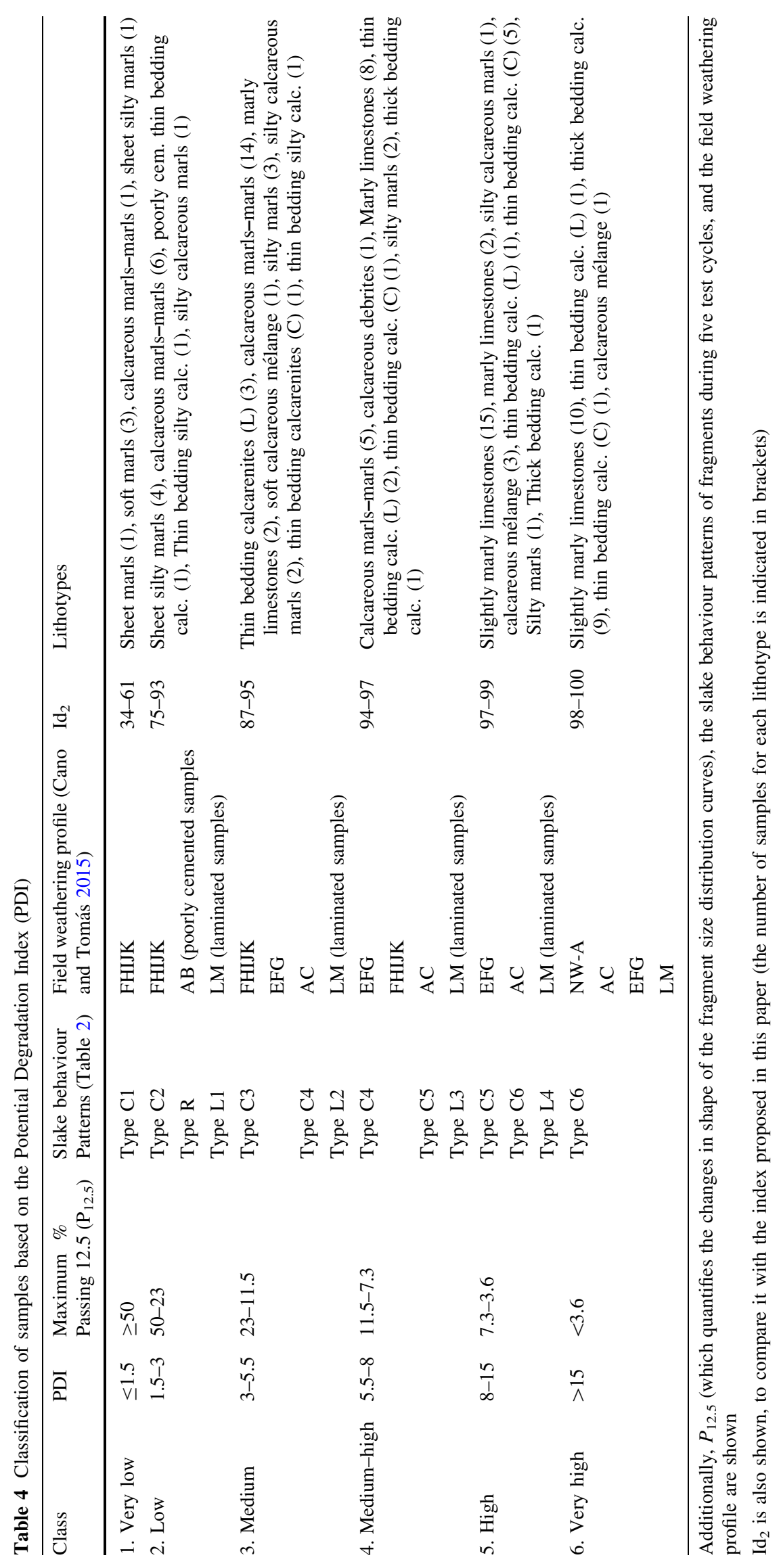



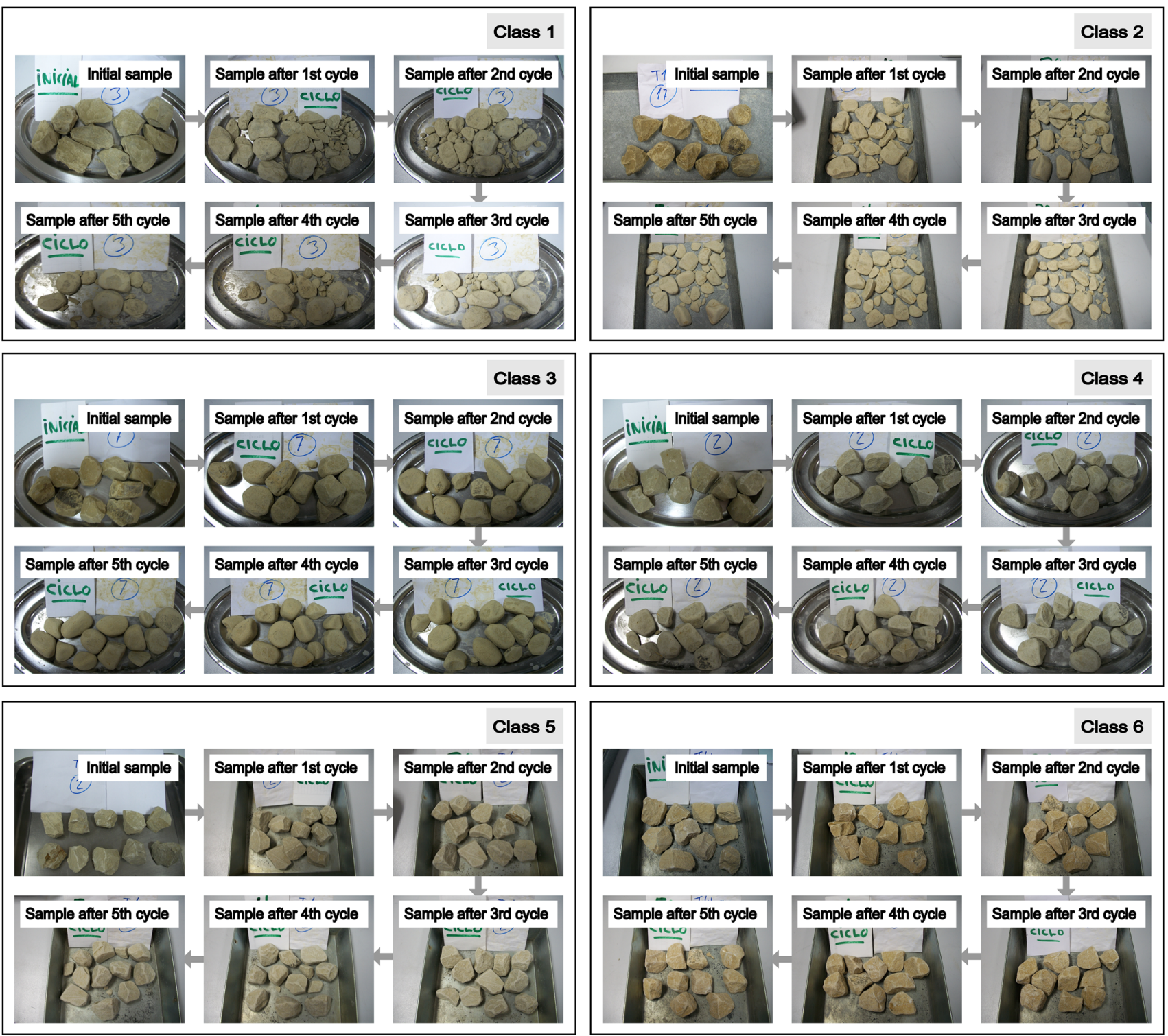

Fig. 9 Models representing each class of slaking behaviour, resulting from the analysis of fragments retained in the drum throughout the five slake durability test cycles

laminated or poorly cemented texture. Where the samples were compact, the slake behaviour patterns C1-C5 corresponded directly with the first five proposed classes, giving an FHIJK or EFG weathering profile. The laminated samples behaved differently, as the fragments could not become rounded owing to the fact that they slid around the drum. The slake behaviour patterns of the laminated samples (L1-L4) corresponded to classes $2-5$, respectively. The least durable laminar samples (class 1) behaved in a similar manner to the least durable compact samples (i.e. type $\mathrm{C} 1$ ), and in the same way the most durable laminar samples (class 6) behaved similarly to type C6 samples (Table 4).

The samples with an AC weathering profile (the most durable as observed in the field) had a slaking behaviour class equal or greater to "medium" (class 3), and their slake behaviour pattern was always one type greater than that which would be expected for rocks of their class, except for class 6 , where they coincided. Where the samples were poorly cemented, the behaviour during the slake cycles was also unusual as the fragments only degraded by rounding, without fracturing and maintaining the same number of fragments (although reduced in size). These samples corresponded to Class 2. Finally, class 6 samples always showed a C6 type slake behaviour pattern, independently of whether they were laminar or compact, and corresponded to the most durable weathering profiles (NW-A, AC, EFG and LM) (Table 4).

It may be observed in Tables 4 and 5 that there is no biunivocal relationship between any one lithotype and 

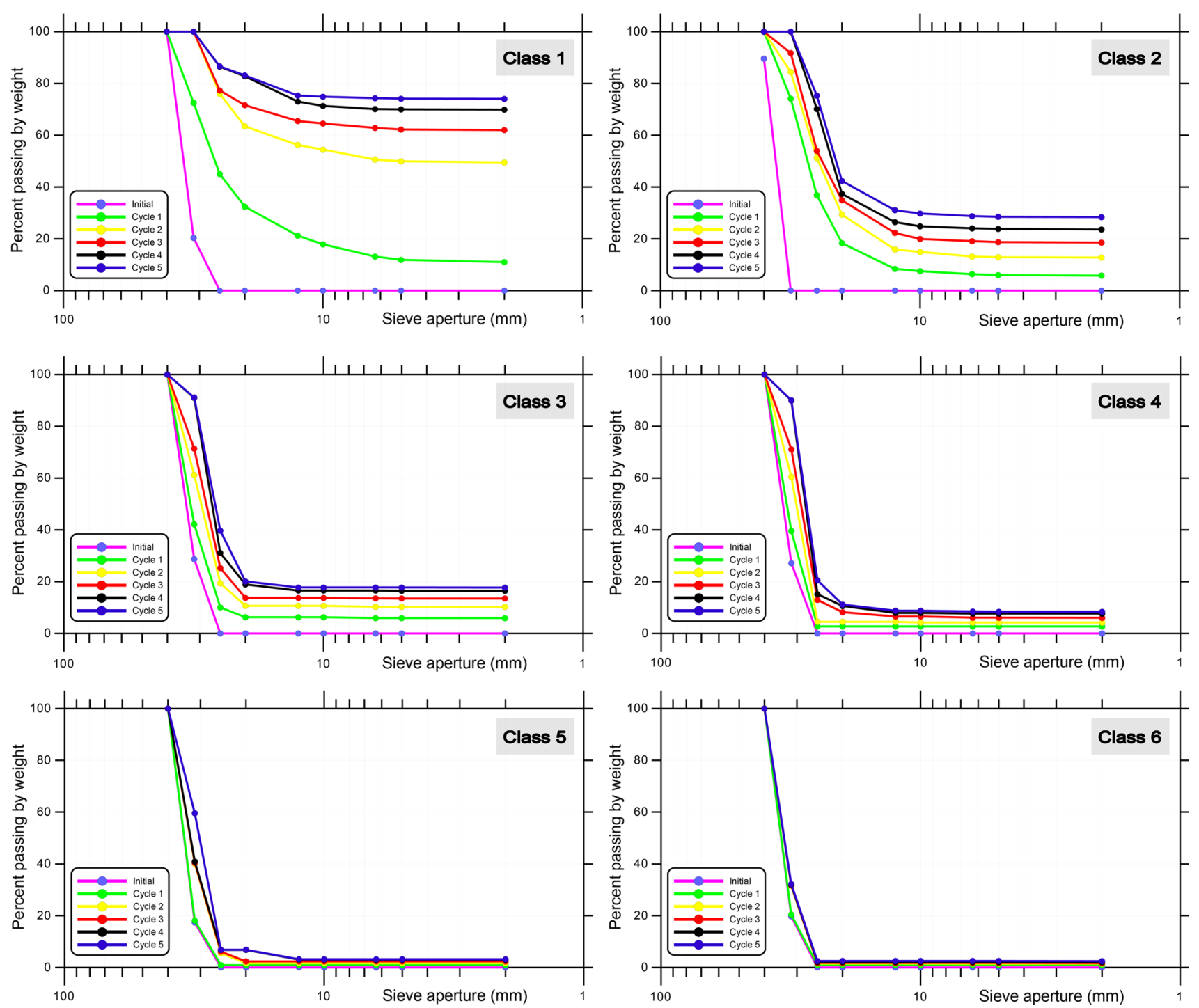

Fig. 10 Models representing each class of slaking behaviour, representing the changes in shape in the fragment size distribution curves throughout the five cycles of the slake durability test. Note that the higher the class number the better the slake behaviour of the sample

durability class, or fragment degradation behaviour. This was also reflected in the in situ behaviour observed (weathering profile). This is understandable when considering that the samples were identified using field criteria based on a simplified geological classification of rocks based on their genetic category, structure, composition and grain size (Geological Society of London 1977). Although instrument-based techniques were used to identify mineralogy, there does not appear to be a clear relationship between mineralogy and durability. This is probably because durability is affected by other factors, such as the microfabric or microscopic texture of the rock (MartínezBofill et al. 2004; Kaufhold et al. 2013; Cano and Tomás 2015). However, it is of greater relevance to note that using this methodology, a particular sample will show a particular PDI value, which allows it to be categorized according to its slaking behaviour, and hence allow its susceptibility to long-term weathering in a slope to be evaluated.

If the range of $\mathrm{Id}_{2}$ values is analysed and compared with the proposed new PDI parameter, it may be clearly observed that the use of $\mathrm{Id}_{2}$ overstates the slaking resistance of the carbonate samples in this study by at least one class.

The different samples, classified in six categories based on their PDI, have been also associated with their maximum percent of sample passing through the $12.5 \mathrm{~mm}$ sieve (P12.5), the slake behaviour patterns of fragments during five test cycles, the field weathering profile and Id 2 index. Additionally, the lithotypes have been associated with their corresponding classes, including the number of samples and allowing the most representative lithologies corresponding to each class to be shown (Table 4). 


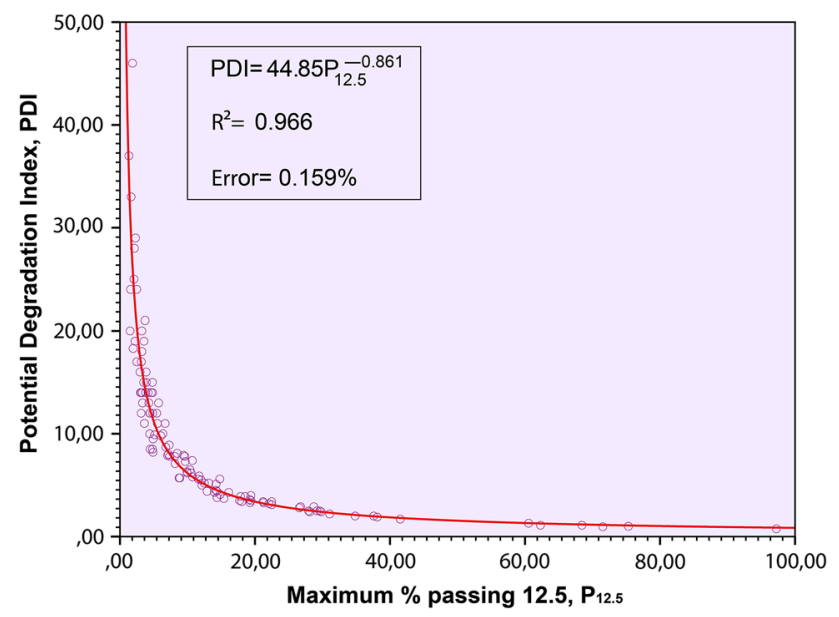

Fig. 11 Correlation between potential degradation index (PDI) and maximum percentage of sample passing through the sieve of $12.5 \mathrm{~mm}$ $\left(P_{12.5}\right)$ for the 117 samples
If the results are analysed according to lithotypes, a clear relationship may be observed between carbonate content and durability - although this is not the determining factor, for reasons discussed previously. However, there is a general trend in the slaking behaviour (classes 1-6) of each lithological group. The thick bedding calcarenites mainly showed a "very high" durability, with a type C6 slake behaviour pattern, corresponding to the NW-A field weathering profile. Slightly marly limestones exhibited a high or very high durability, their slake behaviour pattern was type C5 and C6 and corresponded to the EFG field weathering profile. Calcareous mélange mainly showed a "high" durability, with a type C5 and C6 slake behaviour pattern, corresponding to the AC field weathering profile. Thin bedding calcarenites (compact) mainly exhibited "high" durability, their slake behaviour pattern was type $\mathrm{C} 5$, corresponding to the $\mathrm{AC}$ field weathering profile.

Table 5 Slaking classification of Alicante's carbonate Flysch lithotypes

\begin{tabular}{|c|c|c|c|c|c|c|c|c|c|}
\hline $\begin{array}{l}\text { Mineralogy and } \\
\text { classes of durability } \\
\rightarrow\end{array}$ & $\mathrm{Cb}(\%)$ & Phy (\%) & Qtz $(\%)$ & $\begin{array}{l}\text { Very low } \\
(\mathrm{PDI} \leq 1.5)\end{array}$ & $\begin{array}{l}\text { Low } \\
\text { (PDI: } \\
1.5-3 \text { ) }\end{array}$ & $\begin{array}{l}\text { Medium } \\
\text { (PDI: } \\
\text { 3-5.5) }\end{array}$ & $\begin{array}{l}\text { Medium- } \\
\text { high (PDI: } \\
5.5-8)\end{array}$ & $\begin{array}{l}\text { High } \\
\text { (PDI: } \\
8-15)\end{array}$ & $\begin{array}{l}\text { Very high } \\
(\text { PDI }>15)\end{array}$ \\
\hline $\begin{array}{l}\text { Thick bedding } \\
\text { calcarenites }\end{array}$ & $92.5 \pm 4.2$ & $5.4 \pm 3.0$ & $2.1 \pm 1.6$ & & & & C5 & C6 & C6 \\
\hline $\begin{array}{l}\text { Slightly marly } \\
\text { limestones }\end{array}$ & $82.9 \pm 3.2$ & $12.5 \pm 2.5$ & $4.6 \pm 1.2$ & & & & & C5 & C6 \\
\hline Calcareous mélange & $87.5 \pm 2.4$ & $9.3 \pm 1.9$ & $3.2 \pm 0.6$ & & & & & C5-C6 & C6 \\
\hline $\begin{array}{l}\text { Thin bedding } \\
\text { calcarenites }(\mathrm{C})\end{array}$ & $78.3 \pm 5.4$ & $14.7 \pm 3.7$ & $7.0 \pm 2.5$ & & & $\mathrm{C4}$ & - & C5 & C6 \\
\hline $\begin{array}{l}\text { Thin bedding } \\
\text { calcarenites }(\mathrm{L})\end{array}$ & $72.1 \pm 9.8$ & $18.5 \pm 7.2$ & $3.3 \pm 2.3$ & & & C3-L2 & $\mathbf{L 3}$ & L4 & C6 \\
\hline Calcareous debrites & $84.8 \pm 0.0$ & $11.2 \pm 0.0$ & $4.0 \pm 0.0$ & & & & - & & \\
\hline Marly limestones & $79.0 \pm 2.6$ & $15.3 \pm 2.4$ & $5.7 \pm 0.7$ & & & $\mathrm{C} 2-\mathrm{C3}$ & $\mathrm{C4}$ & C5 & \\
\hline $\begin{array}{l}\text { Silty calcareous } \\
\text { marls }\end{array}$ & $82.4 \pm 3.9$ & $12.7 \pm 2.1$ & $5.0 \pm 1.9$ & & C2 & $\mathbf{C 3}$ & & $\mathrm{C4}$ & \\
\hline Silty marls & $74.7 \pm 3.1$ & $17.8 \pm 2.6$ & $7.6 \pm 0.7$ & & & - & - & - & \\
\hline $\begin{array}{l}\text { Calcareous marls- } \\
\text { marls }\end{array}$ & $75.0 \pm 3.2$ & $17.5 \pm 2.6$ & $7.5 \pm 1.1$ & C1 & $\mathrm{C2}$ & $\mathbf{C 3}$ & $\mathrm{C4}$ & & \\
\hline $\begin{array}{l}\text { Soft calcareous } \\
\text { mélange }\end{array}$ & $84.2 \pm 0.0$ & $11.7 \pm 0.0$ & $4.2 \pm 0.0$ & & & $\mathbf{C 3}$ & & & \\
\hline $\begin{array}{l}\text { Thin bedding silty } \\
\text { calc. }\end{array}$ & $70.0 \pm 11.7$ & $20.0 \pm 9.7$ & $10.1 \pm 2.1$ & & L1 & $\mathbf{C 3}$ & & & \\
\hline Sheet silty marls & $68.5 \pm 6.8$ & $21.4 \pm 6.6$ & $10 \pm 1.4$ & C1 & $\mathrm{C2}$ & & & & \\
\hline $\begin{array}{l}\text { Poorly cem. thin } \\
\text { bedding calc. }\end{array}$ & $74.7 \pm 0.0$ & $19 \pm 0.0$ & $6.4 \pm 0.0$ & & $\mathbf{R}$ & & & & \\
\hline Soft marls & $75.4 \pm 3.8$ & $16.7 \pm 3.0$ & $7.7 \pm 0.9$ & C1 & & & & & \\
\hline Sheet marls & $75.7 \pm 3.7$ & $16.9 \pm 2.5$ & $6.5 \pm 0.0$ & C1 & & & & & \\
\hline
\end{tabular}

Each lithology is associated with a particular slake behaviour pattern and different categories of durability based on Potential Degradation Index. Additionally, mineralogy is shown for each lithology

$C b$ carbonates, dolomite plus calcite, $Q t z$ quartz, Phy phyllosilicates. $C 1, C 2, C 3, C 4, C 5, L 1, L 2, L 3, L 4$ and $R$ are the different slaking behaviour patterns.

Bold values indicate Very low (PDI $\leq 5)$ to Very high (PDI $>15)$ are the six categories of durability based on Potential Degradation Index 
The behaviour of the thin bedding calcarenites (laminated) was highly variable, oscillating between "medium" and "very high" durability. Their slake behaviour pattern was also variable, although it corresponded exclusively to the LM field weathering profile. When sampling from the slopes in the study area, only one layer of Calcareous debrites was detected, which were classified as "mediumhigh" durability. No data were available for the slake behaviour pattern, and the field weathering profile was AD.

Marly limestones mainly exhibited "medium-high" durability, their slake behaviour pattern was type $\mathrm{C} 4$, corresponding to the EFG field weathering profile. The behaviour of the Silty calcareous marls was very variable, as values indicating both "low" and "high" durability, and intermediate classes, were obtained. Data on the slaking behaviour pattern were not available, and the field weathering profile was exclusively FHIJK. The behaviour of the silty marls also varied greatly, as they were classed as having "medium" to "high" durability. Data on the slaking behaviour pattern were not available, and the field weathering profile was EFG, exclusively. The calcareous marlsmarls varied between "low" and "medium-high" durability, with a type C2-C4 slake behaviour pattern. However, the majority of the samples exhibited a "medium" durability with a type C3 slake behaviour pattern, corresponding exclusively to the FHIJK field weathering profile.

The only sample of soft calcareous mélange detected in this study showed a "medium" durability, slake behaviour pattern $\mathrm{C} 3$ and corresponded to the LM field weathering profile. The thin bedding silty calcarenites had a "low" to "medium" durability, L1-C3 slake behaviour pattern and LM field weathering profile. Sheet silty marls mainly exhibited a low durability. Their slake behaviour pattern was type $\mathrm{C} 2$, which corresponded to the FHIJK field weathering profile. The only sample of poorly cemented thin bedding calcarenites detected in the study area showed a low durability. The slake behaviour pattern was type R, corresponding to the $\mathrm{AB}$ field weathering profile. Finally, soft marls and sheet marls were the least durable lithotypes, with a "very low" durability, and a type $\mathrm{C} 1$ slake behaviour pattern which corresponded to the FHIJK field weathering profile (Table 5).

\section{Conclusions}

The classification of carbonate rocks according to their slaking behaviour using the $\mathrm{Id}_{\mathrm{i}}$ indices (Franklin and Chandra 1972; Gamble 1971) does not accurately reflect the weathering behaviour observed in situ. The use of only one sieve size $(2 \mathrm{~mm})$ in the laboratory does not adequately explain slaking behaviour, since the study of the fragments retained in the drum shows evidence of degradation which is not reflected in the results given by the slake durability test.

A new index based on changes in the disintegration ratio $\left(D_{\mathrm{RP}}\right.$; Eq. (1), Fig. 5) throughout five slaking cycles-the potential degradation index [PDI; Eq. (3)] has been proposed as an alternative to the $\mathrm{Id}_{2}$ index. This index takes into account the degradation of the sample fragments retained in the $2 \mathrm{~mm}$ drum, as well as changes in these fragments throughout the experimental process. This has allowed six durability classes to be established to describe slaking behaviour: very low, low, medium, medium-high, high and very high durability. These classes also agree more closely with weathering behaviour patterns observed in the field.

The results indicate that the $\mathrm{Id}_{2}$ index overstates the slaking resistance of the carbonate rock samples tested by at least one class.

This methodology has also allowed the samples to be grouped according to slake behaviour patterns, which take into account changes in morphology in the fragments retained in the drum after each cycle. Additionally, these parameters have been related to the field weathering profiles defined by Cano and Tomás (2015), which allowed the results of laboratory slake tests to be compared with weathering resulting from long-term exposure to natural climactic conditions observed in the field.

Additionally, a correlation has been proposed between the potential degradation index (PDI) and the maximum percentage of sample passing through the $12.5 \mathrm{~mm}$ sieve $\left(P_{12.5}\right)$, which is a less laborious parameter to obtain, and hence is considered to be more adequate for practitioners.

Acknowledgments This work was funded by the University of Alicante under the project GRE14-04, the Ministerio de Economía y Competitividad del Gobierno de España in the framework of the projects TIN2014-55413-C2-2-P and TEC2011-28201-C02-02. The authors wish to express their sincere thanks to Dr. T. Miranda for comments made during Dr. M. Cano's stay at the University of Minho (funded by the University of Alicante), which have substantially improved this work.

Open Access This article is distributed under the terms of the Creative Commons Attribution 4.0 International License (http://crea tivecommons.org/licenses/by/4.0/), which permits unrestricted use, distribution, and reproduction in any medium, provided you give appropriate credit to the original author(s) and the source, provide a link to the Creative Commons license, and indicate if changes were made.

\section{References}

Agencia Estatal de Meteorología (AEMET) (2012) Guía resumida del clima en España 1981-2010, Madrid. Available in http://www. aemet.es/es/conocermas/publicaciones. Accessed 3 Nov 2015 
American Society for testing and Materials (ASTM) (2004) Standard test method for slake durability of shales and similar weak rocks (D4644-04), Philadelphia

American Society for Testing and Materials (ASTM) (2007a) Standard test method for particle-size analysis of soils (D422-63(2007) e2. West Conshohocken, PA

American Society for testing and Materials (ASTM) (2007b) Standard test method for rapid determination of carbonate content of soils [ASTM D4373 - 02(2007)], Philadelphia

Bell FG, Entwisle DC, Culshaw MG (1997) A geotechnical survey of some British Coal measures mudstones, with particular emphasis on durability. Eng Geol 46:115-129

Cano M, Tomás R (2013a) Characterization of the instability mechanisms affecting slopes on carbonatic Flysch: Alicante (SE Spain), case study. Eng Geol 156:68-91

Cano M, Tomás R (2013b) Assessment of corrective measures for alleviating slope instabilities in carbonatic Flysch formations: Alicante (SE of Spain) case study. Bull Eng Geol Environ 72(3-4):509-522

Cano M, Tomás R (2015) An approach for characterising the weathering behaviour of Flysch slopes applied to the carbonatic Flysch of Alicante (Spain). Bull Eng Geol Environ 74:443-463

Czerewko MA, Crips JC (2001) Assessing the durability of mudrocks using the modified jar slake index test. Q J Eng Geol Hydrogeol 34(2):153-163

Dick JC, Shakoor A (1995) Characterizing durability of mudrocks for slope stability purposes. Geol Soc Am Rev Eng Geol X 5:121-130

Dick JC, Shakoor A, Wells NA (1994) A geological approach toward developing a mudrock durability classification system. Can Geotech J 31(5):17-27

Erguler ZA, Shakoor A (2009) Quantification of fragment size distribution of clay-bearing rocks after slake durability testing. Environ Eng Geosci 15(2):81-89

Erguler ZA, Ulusay R (2009) Assessment of physical disintegration characteristics of clay-bearing rocks: disintegration index test and a new durability classification chart. Eng Geol 105:11-19

Franklin JA, Chandra A (1972) The slake-durability test. Int J Rock Mech Mining Sc. 9:325-341

Gamble JC (1971) Durability-Plasticity Clasification of Shales and other Argillaceous Rocks. Ph. D. Thesis. University of Illinois

Gautam TP, Shakoor A (2013) Slaking behavior of clay-bearing rocks during a one-year exposure to natural climatic conditions. Eng Geol 166:17-25

Gautam TP, Shakoor A (2015) Comparing the Slaking of ClayBearing Rocks Under Laboratory Conditions to Slaking Under Natural Climatic Conditions. Rock Mech Rock Eng. doi:10. 1007/s00603-015-0729-7

Geological Society of London (1977) The description of rock masses for engineering purposes: report by the Geological Society Engineering Group Working Party. Q J Eng Geol Hydrogeol 10:55-388

Gökçeoğlu C, Ulusay R, Sönmez H (2000) Factors affecting the durability of selected weak and claybearing rocks from Turkey, with particular emphasis on the influence of the number of drying and wetting cycles. Eng Geol 57:215-237

Guerrera F, Estévez A, López-Arcos M, Martín-Martín M, MartínPérez JA, Serrano F (2006) Paleogene tectono-sedimentary evolution of the Alicante Trough (External Betic Zone, SE Spain) and its bearing on the timing of the deformation of the South-Iberian Margin. Geodin Acta 19(2):87-101

Hack HRGK (1998) Slope Stability Probability Classification, 2nd ed.: Ph.D. Thesis, ITC, Delft, The Netherlands
Hack HRGK, Huisman M (2002) Estimating the intact rock strength of a rock mass by simple means. In: van Rooy JL, Jermy CA (eds) Engineering geology for developing countries-proceedings of 9th congress of the international association for engineering geology and the environment: south african institute of engineering geologists (SAIEG). Durban, South Africa, pp 1971-1977

Hoek E, Carranza-Torres C, Corkum B (2002) Hoek-Brown failure criterion-2002 edition. Proceedings of NARMS-Tac 1:267-273

INGEMISA (Investigaciones geológicas y mineras, S. A.), Auernheimer C (1991) Mapa geocientífico de la provincia de Alicante. Conselleria d'Administració Pública, Valencia, Agència de Medi Ambient, p 93

ISRM (1981) Rock characterization. In: Brown ET (ed) Testing and monitoring-ISRM suggested methods. Pergamon press, Oxford, p 211

Kaufhold A, Gräsle W, Plischke I, Dohrmann R, Siegesmund S (2013) Influence of carbonatic content and micro fabrics on the failure strength of the sandy facies of the Opalinus Clay from Mont Terri (underground rock laboratory). Eng Geol 156:111-112

Martin JD (2004) Using XPowder: A software package for Powder $\mathrm{X}$-Ray diffraction analysis

Martínez-Bofill J, Corominas J, Soler A (2004) Behaviour of the weak rocks cutslopes and their characterization using the results of the Slake Durability Test. In: Lecture notes in Earth Sciences. 104. Engineering Geology for Infrastructure Planing in Europe

Miščcević P, Vlastelica G (2011) Durability characterization of marls from the region of Dalamtia. Croatia. Geotech Geol Eng 29:771-781

Miščcević P, Vlastelica G (2014) Impact of weathering on slope stability in soft rock mass. J Rock Mech Geotech Eng 6:240-250

Moon VG, Beattie AG (1995) Textural and microstructural influences on the durability of Waikato coal measures mudrocks. Q J Eng Geol 14:255-279

Nicholson DT (2001) Deterioration of Excavated Rockslopes: mechanisms, morphology and assessment: Ph.D. Thesis, University of Leeds, Leeds, UK

Santi PM (1998) Improving de jar slake, slake index, and slake durability tests for shales. Environ Eng GeoSci IV(3):385-396

Richardson DN, Long JD (1987) The sieve slake durability test. Bull Ass Eng Geol 2(5):247-258

Robert M, Tessier D (1974) Méthode de préparation des argiles des sols pour des études minéralogiques. Annal Agronom 25(6):859-882

Romana M (1993) A geomechanical classification for slopes: slope mass rating. Comp Rock Eng 3:575-599

Sabatakakis N, Tsiambaos G, Koukis G (1993) Index properties of soft marly rocks of the Athens basin, Greece. Geotech Eng Hard Soils-Soft Rocks. Anagnostopoulos A (eds) Rotterdam, Balkema, pp 275-279

Shakoor A (1995) Slope stability considerations in differentially weathered mudrocks. Geol Soc Am Rev Eng Geol X 1995(5):131-138

Taylor RK (1988) Coal Measures mudrocks: composition, classification and weathering processes. Q J Eng Geol 21:85-99

Ulusay R, Arikan F, Yoleri MF, Caglan D (1995) Engineering geological characterization of coal mine waste material and an evaluation in the context of back-analysis of spoil pile instabilities in a strip mine SW Turkey. Eng Geol 40:77-101

Vera JA (2004) Geología de España. Sociedad Geológica de España, Instituto Geológico y Minero de España 